\title{
Polarization Maintaining Highly Birefringent Small Mode Area Photonic Crystal Fiber at Telecommunication Window
}

\author{
S.S. Mishra ${ }^{\#}$ and Vinod K. Singh ${ }^{*}$ \\ Department of Applied Physics \\ Indian School of Mines, Dhanbad-826004 \\ Jharkhand, India \\ \#suvendumohan_2006@yahoo.co.in \\ *singh.vk.ap@ismdhanbad.ac.in
}

\begin{abstract}
In this paper a highly polarization maintaining birefringent photonic crystal fiber at telecommunication window is reported via Full-Vectorial Finite Element Method (FV-FEM). By taking triangular lattice of three ring hexagonal structure PCF with suitable designing parameters such as symmetrical elliptical hole along radial axis of ellipticity $a / b=5 \mu m$, air hole diameter $d=1 \mu \mathrm{m}$ and pitch $\Lambda=2.3 \mu \mathrm{m}$, high birefringence $\left(2.437 \times 10^{-3}\right)$ with small effective mode area $\left(9.47 \mu \mathrm{m}^{2}\right)$ and beat length $(0.64 \mathrm{~cm})$ are found at wavelength $1.55 \mu \mathrm{m}$.
\end{abstract}

Index Terms- Birefringence, Effective mode area, Full-Vector Finite Element Method, Photonic crystal fiber

\section{INTRODUCTION}

Nowadays, Photonic crystal fibers (PCFs) have diverse applications in telecommunications, sensors, interferometry, soliton, lasers, medical instrumentations and various polarizationsensitive devices etc. [1]-[3]. PCFs are made from single material such as silica glass with an array of microscopic air channels running along its length. Essentially, photonic crystals contain regularly repeating internal regions of high and low dielectric constant. The governing property of the crystals is a photonic band gap: ranges of frequency for which light cannot propagate through the structure [4].The primary difference between PCFs and conventional fiber is that photonic crystal fibers feature an air-silica cross section, where as standard optical fibers have all glass cross-sections of varying refractive index. Polarization Maintaining Photonic Crystal Fiber (PMPCF) has different elliptical air holes along central 
axis of the core region which creates an effective index difference between the two polarization modes. These modes can be verified theoretically as well as experimentally [5][8]. PMPCFs can exhibit high birefringence, provide small effective mode area for very large wavelength range as compared to conventional polarization maintain optical fibers [9]-[12].

Due to complex structure of PCF, different numerical techniques has been used to study the different properties of PMPCF such as Finite Element Method (FEM)[13], Improved Effective Index Method[14], Finite Difference Time Domain Method (FDTDM)[15], Plane Wave Expansion Method (PWEM)[16], Multi-Pole Method [17]. Among these methods, Full-Vectorial Finite Element Method (FVFEM) is best suitable to calculate mode field pattern, effective refractive index, effective mode area, and birefringence properties of the fiber. The FV-FEM technique takes less computational time and requires less computer memory and provides accurate results at higher wavelength. By manipulating elliptical air hole size along radial axis width ' $a$ ' and height ' $b$ ', pitch ' $\Lambda$ ', and air hole diameter ' $d$ ' of the proposed PCF, it is possible to achieve small effective mode area and high birefringence at wavelength $1.55 \mu \mathrm{m}$.

\section{Full-Vector Finite Element Method}

The Full-Vectorial Finite element method (FV-FEM) is advantageous in complex geometries of photonic crystal fiber. It is a full vector implementation for both propagation and leaky modes and cavity modes for two dimensional Cartesian cross sections in cylindrical coordinates. First and second order interpolant basis are provided for each triangular elements. PML (Perfectly matched layer) boundary conditions is employed at computational domain for evaluating effective mode area and birefringence of the proposed PCF [18].We begin with the source-free time harmonic form of the vector wave equation in an arbitrary, anisotropic lossy media [19].

$$
\nabla \times\left\{\frac{1}{\vec{s}} \times(\nabla \times \vec{E})\right\}-K_{0}^{2} \overrightarrow{E_{r}} \vec{E}=0
$$

The complex diagonal tensors $\vec{s}$ and $\in_{\boldsymbol{r}}$ represent co-ordinates stretching and the dielectric material respectively [20-25]. The mathematical details are given elsewhere [26].

Finally, we will get matrix generalized eigen-values equation of the form

$$
\left(A-n_{e f f}^{2} B\right)\left(E_{T i}\right)=(0)
$$


Where $\mathrm{A}$ and $\mathrm{B}$ represent tri-diagonal matrices and $\mathrm{E}_{\mathrm{Ti}}$ denotes for transverse electric field. The effective refractive index of the fundamental mode is given as $n_{\text {eff }}=\beta / k_{0}$, where $\beta$ is the propagation constant, $\mathrm{k}_{0}=2 \pi / \lambda$ is the free space wave number.

\section{RESUltS AND DisCuSSIONS}

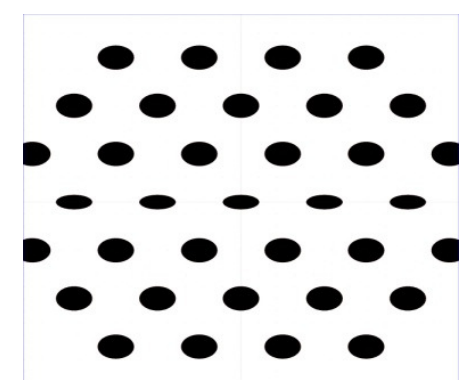

(i)

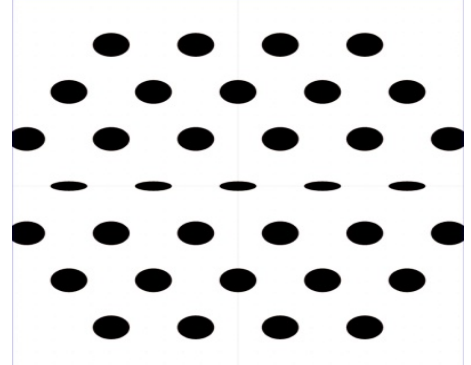

(ii)

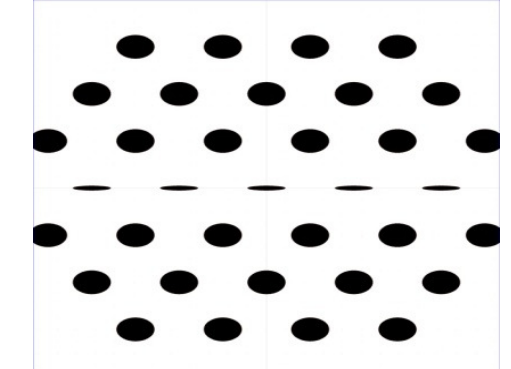

(iii)

Fig.1 ( Proposed Polarization maintaining birefringent photonic crystal fiber structures)

Structures parameter

(i) $\mathrm{d}=1 \mu \mathrm{m}, \Lambda=2.3 \mu \mathrm{m}$ and $\mathrm{a} / \mathrm{b}=5 \mu \mathrm{m}$

(ii) $\mathrm{d}=1 \mu \mathrm{m}, \Lambda=2.3 \mu \mathrm{m}$ and $\mathrm{a} / \mathrm{b}=2.5 \mu \mathrm{m}$

(iii) $\mathrm{d}=1 \mu \mathrm{m}, \Lambda=2.3 \mu \mathrm{m}$ and $\mathrm{a} / \mathrm{b}=1.66 \mu \mathrm{m}$

In this paper, a new type of polarization maintaining highly birefringent triangular lattice three-ring hexagonal PCF is proposed. Symmetrically elliptical air holes are introduced along radial axis of the fiber with keeping all other air hole diameter as same. By using elliptical air hole the degeneracy splits significantly and photonic band gap also changes which causes increase in birefringence. The key point is to destroy the symmetry of the structure and make the effective index difference between the two orthogonal polarization states. The black regions are air hole and white regions are silica, where the refractive indices of silica and air holes are taken as 1.45 and 1 respectively.

Above structures are then analyzed by FV-FEM. The diameter of all identical air holes and pitch (distance between the two center of the consecutive air hole) throughout the simulation were taken as fixed e.g. $\mathrm{d}=1 \mu \mathrm{m}$ and $\Lambda=2.3 \mu \mathrm{m}$ respectively. 


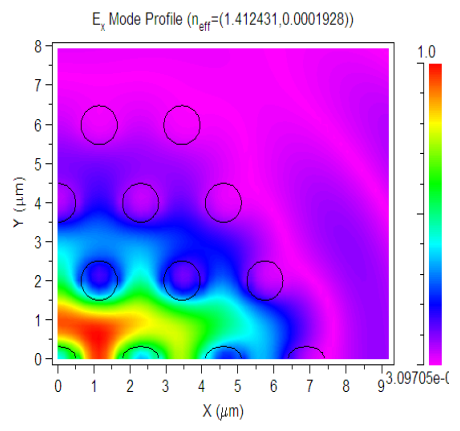

(i)

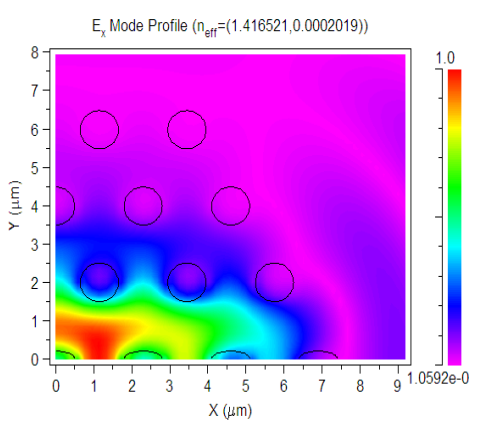

(ii)

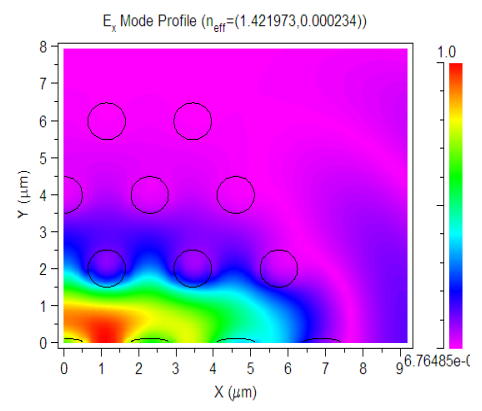

(iii)

Fig.2 Simulated Transeverse Electric Mode field pattern (one fourth part) of Birefringence PCF for all three structures (i) $\mathrm{d}=1 \mu \mathrm{m}, \Lambda=2.3 \mu \mathrm{m}$ and $\mathrm{a} / \mathrm{b}=5 \mu \mathrm{m}$,(ii) $\mathrm{d}=1 \mu \mathrm{m}, \Lambda=2.3 \mu \mathrm{m}$ and $\mathrm{a} / \mathrm{b}=2.5 \mu \mathrm{m}$ and (iii) $\mathrm{d}=1 \mu \mathrm{m}, \Lambda=2.3 \mu \mathrm{m}$ and $\mathrm{a} / \mathrm{b}=1.66 \mu \mathrm{m}$ at wavelength $1.55 \mu \mathrm{m}$ respectively.

Initially, the size of symmetrical elliptically air hole is taken as $\mathrm{a} / \mathrm{b}=1.66 \mu \mathrm{m}$ after simulation transverse electric mode field pattern is observed for all structures. The effective mode area can be calculated in operating wavelength range by using eq.(3) via FEMSIM technique [27] for structure (i). Then the elliptical air hole size was varied to $2.5 \mu \mathrm{m}$ and $5 \mu \mathrm{m}$ for other simulation for structures (ii) and (iii) as shown in Fig.1. Mode field patterns of all three structures are shown in Fig 2. Once mode field patterns are known, the effective mode area can be calculated using following formula,

$$
A_{e f f}=\frac{\left(\int_{-=\mid}^{m}|z|^{2} d x d y\right)^{2}}{\int_{-=1}^{m}|E|^{4} d x d y}
$$

From Fig.3, it is observed that the effective mode area of the PCF increases with increasing of wavelength and decreases with decreasing elliptical air hole size in radial axis of the fiber. The effective mode areas were obtained as $11.25 \mu \mathrm{m}^{2}, 10.11 \mu \mathrm{m}^{2}$ and $9.46 \mu \mathrm{m}^{2}$ for three structures (i), (ii) and (iii) respectively at wavelength $1.55 \mu \mathrm{m}$. It is clear that effective mode area is minimum for structure (iii) in comparison to structures (i) and (ii). 


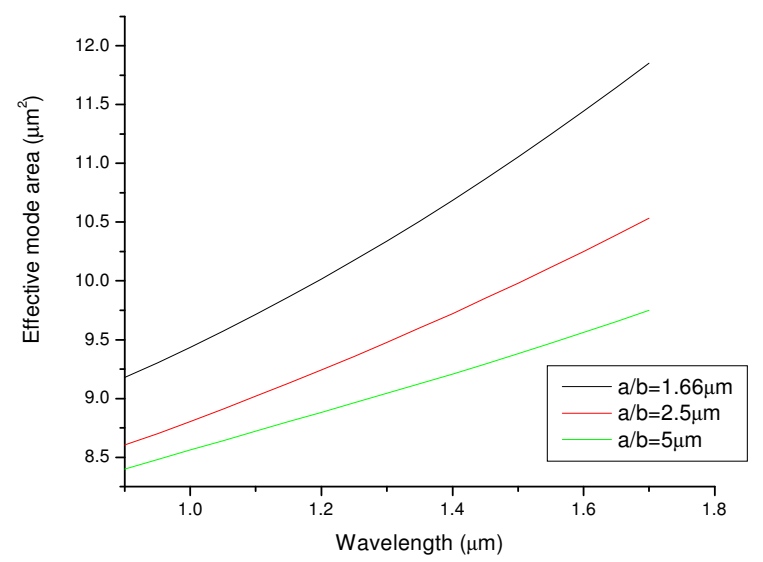

Fig.3 Variation of effective mode area with wavelength of the proposed PCF structures (i) $d=1 \mu \mathrm{m}, \Lambda=2.3 \mu \mathrm{m}$ and $\mathrm{a} / \mathrm{b}=5 \mu \mathrm{m}$,(ii) $\mathrm{d}=1 \mu \mathrm{m}, \Lambda=2.3 \mu \mathrm{m}$ and $\mathrm{a} / \mathrm{b}=2.5 \mu \mathrm{m}$ and (iii) $\mathrm{d}=1 \mu \mathrm{m}, \Lambda=2.3 \mu \mathrm{m}$ and $\mathrm{a} / \mathrm{b}=1.66 \mu \mathrm{m}$ respectively.

By using FEMSIM technique, the birefringence of the proposed fiber is then determined by the difference between the effective indices of two orthogonal polarization modes which is given as

$$
\mathrm{B}=\left|\mathrm{n}_{\mathrm{eff}}^{\mathrm{x}}-\mathrm{n}_{\mathrm{eff}}^{y}\right|
$$

where $\mathrm{n}_{\mathrm{eff}}^{\mathrm{x}}$ and $\mathrm{n}_{\mathrm{eff}}^{\mathrm{y}}$ are the refractive indices of the $\mathrm{x}$-and $\mathrm{y}$-polarized fundamental modes of the fiber respectively. The variation of phase birefringence with wavelength of PCFs is shown in Fig.4. It is clear that phase birefringence increases with increasing wavelength and also increasing with ellipticity of the air hole along radial axis of the fiber. The effective indices of the $\mathrm{x}$ - and $\mathrm{y}$-polarized modes of PCF structure (iii) are $\mathrm{n}_{\mathrm{eff}}^{\mathrm{x}}=1.421973$ and $\mathrm{n}_{\mathrm{eff}}^{\mathrm{y}}=$ 1.419536 respectively giving a phase birefringence $\mathbf{B}=\left|\mathrm{n}_{\mathrm{eff}}^{x_{\mathrm{f}}}-\mathrm{n}_{\mathrm{eff}}^{\mathrm{y}}\right|=2.437 \times 10^{-3}$ at wavelength $1.55 \mu \mathrm{m}$ which is much higher than the structure (i) and (ii) where the phase birefringence of structures (i) and (ii) are $9.24 \times 10^{-4}$ and $1.615 \times 10^{-3}$ respectively. From Fig.5, it is also observed that phase birefringence decreases with increasing normalized frequency of all three structures. The phase birefringence is obtained $2.437 \times 10^{-3}$ for structure (iii) at wavelength $1.55 \mu \mathrm{m}$ and normalized frequency 1.48 . 


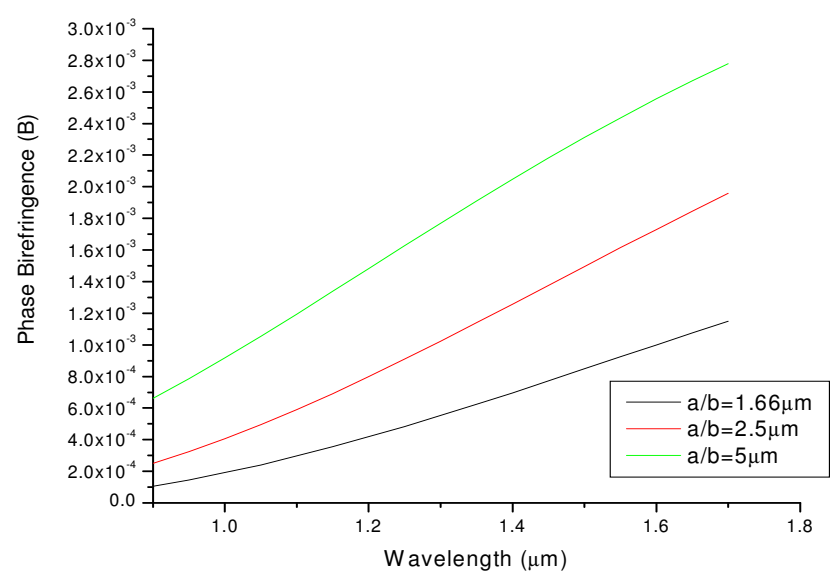

Fig.4 Variation of birefringence with wavelength of the proposed PCF structures (i) $\mathrm{d}=1 \mu \mathrm{m}, \Lambda=2.3 \mu \mathrm{m}$ and a/b=5 $\mu \mathrm{m}$, (ii) $\mathrm{d}=1 \mu \mathrm{m}, \Lambda=2.3 \mu \mathrm{m}$ and $\mathrm{a} / \mathrm{b}=2.5 \mu \mathrm{m}$ and (iii) $\mathrm{d}=1 \mu \mathrm{m}, \Lambda=2.3 \mu \mathrm{m}$ and $\mathrm{a} / \mathrm{b}=1.66 \mu \mathrm{m}$ respectively

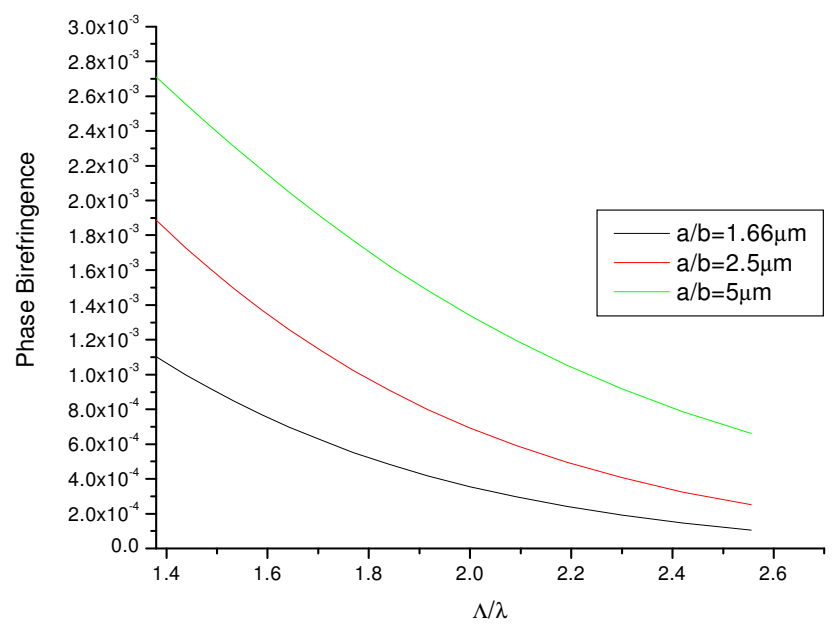

Fig.5 Variation of birefringence with normalized frequency of the proposed PCF structures (i) $\mathrm{d}=1 \mu \mathrm{m}, \Lambda=2.3 \mu \mathrm{m}$ and $\mathrm{a} / \mathrm{b}=5 \mu \mathrm{m}$, (ii) $\mathrm{d}=1 \mu \mathrm{m}, \Lambda=2.3 \mu \mathrm{m}$ and $\mathrm{a} / \mathrm{b}=2.5 \mu \mathrm{m}$ and (iii) $\mathrm{d}=1 \mu \mathrm{m}, \Lambda=2.3 \mu \mathrm{m}$ and $\mathrm{a} / \mathrm{b}=1.66 \mu \mathrm{m}$ respectively

Once phase birefringence can be solved by using FEMSIM technique, the beat length parameter of the proposed PCF can be calculated by using the equation given below

$$
L_{B}=\frac{\lambda}{B}
$$

Where $L_{B}, \lambda$ and $B$ are called beat length, wavelength and birefringence of the fiber respectively.

The beat lengths $\left(\mathrm{L}_{\mathrm{B}}\right)$ are obtained as $1.68 \mathrm{~cm}, 0.96 \mathrm{~cm}$ and $0.64 \mathrm{~cm}$ for structures (i), (ii) and (iii) respectively at wavelength $1.55 \mu \mathrm{m}$. From Fig.6, it is observed that beat length decreases with increasing wavelength as well as elliptical size of the air hole along radial axis of the fiber. It is also observed that beat length decreases with increasing normalized frequency of all three structures PCF as shown in Fig.7. At wavelength $1.55 \mu \mathrm{m}$ at normalized frequency 
1.48 the beat length is obtained $0.64 \mathrm{~cm}$ for structure (iii) which is comparatively smaller than structures (i) and (ii) respectively.

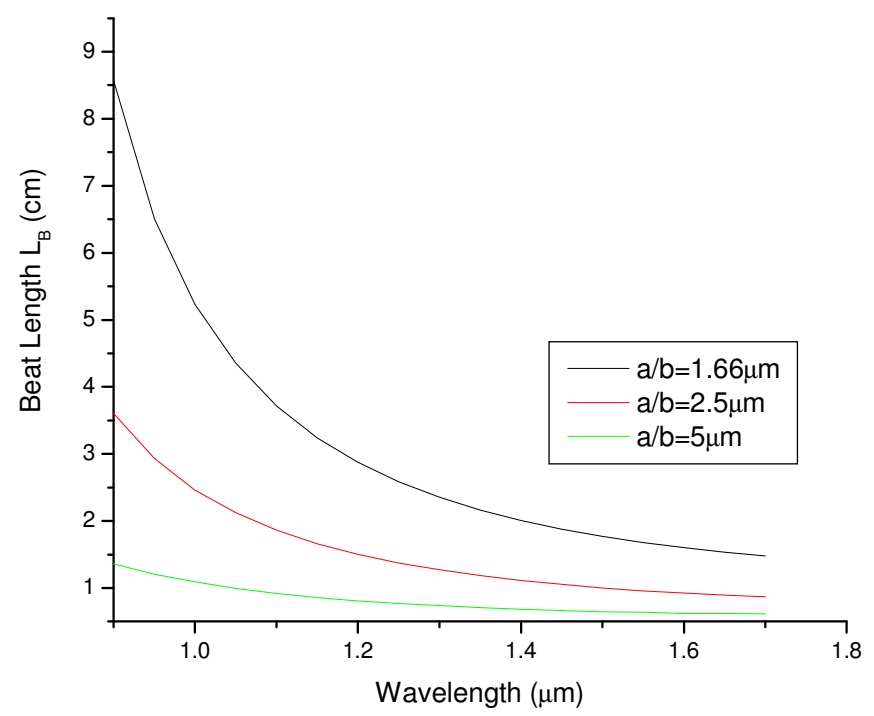

Fig.6 Variation of beat length $\left(L_{B}\right)$ with wavelength of the proposed PCF structures (i)d $=1 \mu \mathrm{m}, \Lambda=2.3 \mu \mathrm{m}$ and $\mathrm{a} / \mathrm{b}=5 \mu \mathrm{m}$, (ii) $\mathrm{d}=1 \mu \mathrm{m}, \Lambda=2.3 \mu \mathrm{m}$ and $\mathrm{a} / \mathrm{b}=2.5 \mu \mathrm{m}$ and (iii) $\mathrm{d}=1 \mu \mathrm{m}, \Lambda=2.3 \mu \mathrm{m}$ and $\mathrm{a} / \mathrm{b}=1.66 \mu \mathrm{m}$ respectively

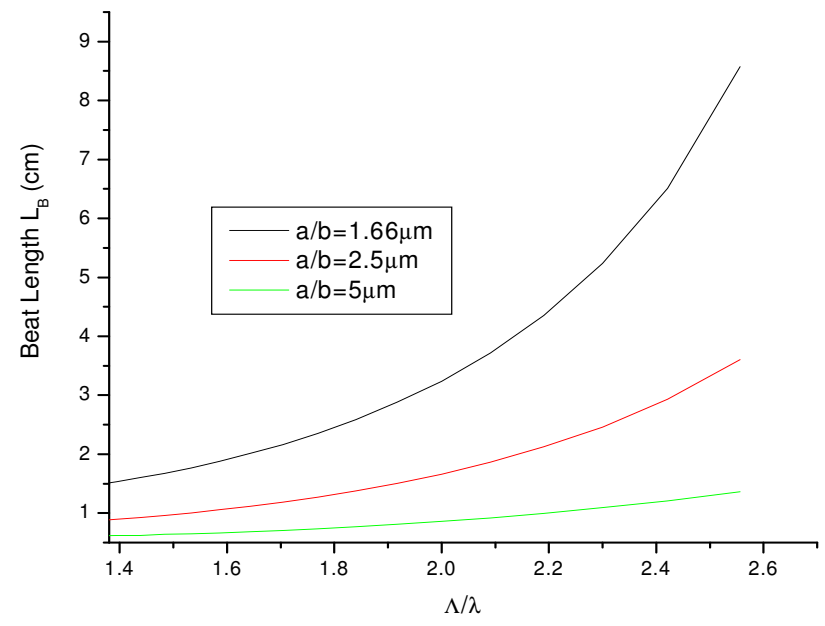

Fig.7 Variation of beat length $\left(\mathrm{L}_{\mathrm{B}}\right)$ with normalized frequency of the proposed PCF structures (i) $\mathrm{d}=1 \mu \mathrm{m}, \Lambda=2.3 \mu \mathrm{m}$ and $\mathrm{a} / \mathrm{b}=5 \mu \mathrm{m}$, (ii) $\mathrm{d}=1 \mu \mathrm{m}, \Lambda=2.3 \mu \mathrm{m}$ and $\mathrm{a} / \mathrm{b}=2.5 \mu \mathrm{m}$ and (iii) $\mathrm{d}=1 \mu \mathrm{m}, \Lambda=2.3 \mu \mathrm{m}$ and $\mathrm{a} / \mathrm{b}=1.66 \mu \mathrm{m}$ respectively

\section{CONCLUSION}

The polarization maintaining highly birefringent small mode area photonic crystal fiber is investigated by Full-Vector Finite Element Method successfully. The simulation results prove that birefringence and effective mode area property mostly depends upon the optimized geometrical fiber parameters such as width and height of symmetrical elliptical hole along 
radial axis of the fiber, air hole diameter, pitch etc. For width $a=1 \mu \mathrm{m}$, height $b=0.2 \mu \mathrm{m}$, air hole diameter $\mathrm{d}=1 \mu \mathrm{m}$ and pitch $\Lambda=2.3 \mu \mathrm{m}$, high birefringence $2.437 \times 10^{-3}$ with small effective mode area $9.47 \mu \mathrm{m}^{2}$ and beat length $0.63 \mathrm{~cm}$ are achieved for structure (iii) at wavelength 1.55 $\mu \mathrm{m}$. This kind of fiber can be used in interferometer and various polarization-sensitive devices.

\section{References}

[1] J. C Knight.,Photonic crystal fiber, Nature 424,847-851(2003).

[2] M. Medhat, N.I. Hendawy and A.A. Zaki, Interferometric Method to Determine the birefringence for an anisotropic material , Egypt.J.Sol.26 (2) 231-239(2003).

[3] O. Frazao, J.M. Baptista and L.Santos, Recent Advances in High-Birefringence Fiber Loop Mirror Sensors, Sensors 7 , 2970-2983(2007).

[4] John D.Joannopoulos, Steven G.Johnson, Joshua N.Winn and Robert D.Meade, “ Photonic Crystals: molding the flow of light” Princeton University Press Princeton and Oxford (2008).

[5]M.Tanaka and M.Fujita, Optical properties of a low-loss polarization maintaining photonic crystal fiber,Optics Express 9 , 676-680(2001).

[6]B.Ortigosa, J.C.Knight, W.J.Wadsworth,T.A.Birks, P.St.J.Russel, Highly birefringent photonic crystal fibers,Optics Letter 25, 1325-1327 (2000).

[7] Y-S.Sun,Y-F. Chau, H-H. Yeh, L-F Shen,T-J. Yang and D.P.Tsai, High birefringence photonic crystal fiber with a complex unit cell of asymmetric elliptical air hole cladding,Applied Optics 46 (22) 5276-5281 (2007).

[8] K.Kishor,R.K.Sinha,A.D.Varshney and J.Singh, Theory and experiment on characterization of polarization maintaining photonic crystal fiber from far field measurements, Proceeding of International conference on Optics and Photonics,ICOP2009, Chandigarh,30 oct-01 Nov.(2009).

[9] G.Tao-rong,Y.Feng-ping,W.Lin,L.Pen, L.Yi-fang and J.Shui-sheng, A kind of photonic crystal fiber with high birefringence and low confinement loss, Optics Letters 4 (2)110-113 (2008).

[10]S.Kawanishi and K.Okamoto, Polarization maintaining holey optical fiber, IEICE Soc.Conf.2000,B-10-153 (in Japanese) (2000).

[11] T-J.Yang, L-F. Shen,Y-F. Chau, M-J.Sung, D.Chen and D.P.Tsai, High birefringence and low loss circular air-holes photonic crystal fiber using complex unit cells in cladding, Optics Communications 281,4334-4338 (2008).

[12]A.K.Ghatak, R.Srivastava, I.F.Faria, K.Thyagarajan and R.Tiwari, Accurate method for characterizing single-mode fibers: theory and experiment, Electronics Letters 19,97-99 (1983).

[13] F. Brechet, J. Marcou, D. Pagnoux and P.Roy, Complete Analysis of the characteristics of propagation into photonic crystal fibers by Finite Element Method, Optical Fiber Technology 6, 181-191 (2000).

[14] A. D. Varshney and R. K. Sinha, Non-Linear Properties of photonic crystal fiber: Improved Effective index Method, Chinese Journal of Physics 47 (2)184-191(2009).

[15] M. Qiu, Analysis of guided modes in photonic crystal fibers using the Finite-Differece Time-Domain Method , Microwave and optical Technology Letters 30 (5) (2001).

[16] L. Zhao-lun, H. Lan-tian and W. Wei, Tailoring Nonlinearity and Dispersion of Photonic crystal Fibers using Hybrid cladding, Brazilian Journal of physics 39 (1) 50-54 (2009).

[17] W. S. Y. Zhao, Y. Bao, S. Li, Z. Zhang and T. Xu, Numerical Simulation and Analysis on mode property of photonic crystal Fiber with high birefringence by Fast Multipole Method, PIRS online 3 (6) 836-841(2007). 
[18] J.Jin, The, Finite Element Method in Electromagnetics, $2^{\text {nd }}$ Ed.,John Wiley \& Sons,New York (2002).

[19] S. Saitoh and M. Koshiba, Full-Vectorial Imaginary-Distance Beam propagation Method based on a finite element scheme:Application to photonic crystal fiber, IEEE JQE 38 (7) 927 (2002).

[20] D.Schulz, C. Glingener, M. Bludszuweit and E. Voges, Mixed Finite element Beam Propagation Method, IEEE JLT 16 (7) $1336(1998)$.

[21] Y. Tsuji and M. Koshiba, Guided- mode and leaky mode Analysis by Imaginary distance beam propagation method based on finite element scheme, IEEE JLT 18 (4) 618 (2000).

[22] M. Koshiba \& Y.Tsuji, Curvilinear Hybrid Edge/Nodal Elements with triangular shape for for guided wave problems, IEEE JLT 18 (5) 737 (2000).

[23] S. Mishra \& V. K. Singh, Photonic Crystal Fiber Analysis by Finite Element Method, Proceeding of International conference, Photonics 2008, Held at IIT Delhi, 242 (2008).

[24] S. Mishra and V. K. Singh, Study of Dispersion properties of hollow core photonic crystal fiber by Finite element Method, Journal of Optoelectronics and Advanced Materials-Rapid Communication 3 (9) 874-878 (2009).

[25] S.S. Mishra and V. K. Singh, Endlessly Single-mode Highly polarization maintaining birefringent photonic crystal fiber with zero dispersion at wavelength at $1.55 \mu \mathrm{m}$, International Journal of Engineering Science and Technology 2 (9) 4521-4526 (2010).

[26] S.S. Mishra and V. K.Singh, Study of Fundamental Propagation Properties of Solid Core Holey Photonic Crystal Fiber in Telecommunication window, Chinese Journal of Physics 48 (5) 592-606 (2010).

[27] FEMSIM , Rsoft Design Group, Ossining, NY 10562 (2003). 